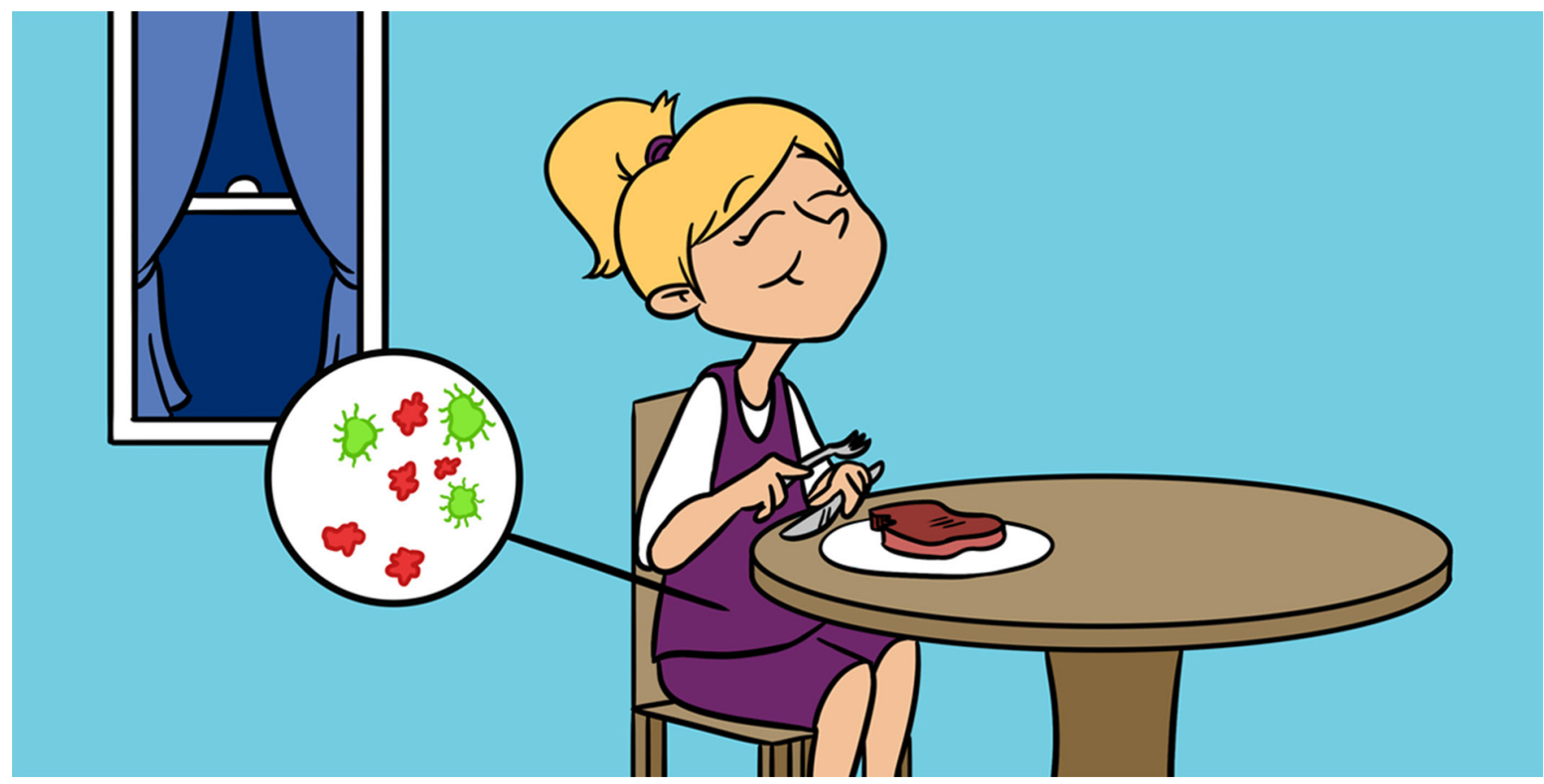

\title{
WHY WE SHOULD NOT EAT RED MEAT AT EVERY SINGLE MEAL
}

\section{Marco Constante ${ }^{1,2 *}$, Vinita Bharat ${ }^{3}$, Amelia Walker ${ }^{1}$ and Manuela M. Santos ${ }^{1,2}$ \\ ${ }^{1}$ Centre de Recherche du Centre Hospitalier de l'Université de Montréal, Montreal, QC, Canada \\ ${ }^{2}$ Department of Medicine, Université de Montréal, Montreal, QC, Canada \\ ${ }^{3}$ Department of Neurosurgery, Stanford University, Stanford, CA, United States}

\section{YOUNG REVIEWERS:}

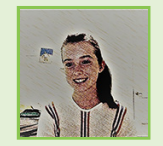

SIENNA

AGE: 12

TYLER

AGE: 11
Right now, inside all of our bodies there is a complex ecosystem made up of bacteria. Often when we think of bacteria, we think of disease, but most bacteria are beneficial and are needed for maintaining our good health. Most of these bacteria live in the gut. Beneficial bacteria in our bodies contribute to our development and help combat the harmful bacteria that might make us sick. Therefore, if the bacterial ecosystem in the gut is out of balance and there are too many of the harmful bacteria, it might lead to certain intestinal diseases. We have studied how heme iron, a type of iron that is found in our blood and in red meat, disturbs the bacterial community in the gut, and ultimately how that affects gut health. We found that high consumption of dietary heme promotes the growth of harmful bacteria, while reducing the number of beneficial ones. 


\section{GUT}

The gut is part of the body's digestive system that deals with all the food and drink that you take into your body. The gut is also called the intestines or bowels, and they are all coiled up to fit inside your belly.

\section{MICROBIOTA}

The collection of microorganisms that live in a certain part of the human body, for example, on the skin, or in the gut. https://kids.frontiersin. org/article/10.3389/ frym.2017.00035

\section{DYSBIOSIS}

An imbalance in the microbial communities in number or type, either in or on the body.

\section{IRON}

Iron is a mineral, and its main purpose is to carry oxygen in red blood cells throughout the body, so cells can produce energy.

\section{Figure 1}

Balanced: The balanced gut microbiota shows a healthy number and mix of beneficial and harmful microbes. Dysbiosis: the gut microbiota in dysbiosis shows more harmful microbes and fewer beneficial microbes, compared with a balanced gut microbiota.

\section{BACTERIA IN THE GUT-THE GOOD AND THE BAD}

The food and drinks that we take into our bodies go through our digestive system, which includes the intestines. The intestines are also called the gut or the bowels. Inside the gut, there are millions and millions of bacteria and other microbes, which we call the gut microbiota. Most of the bacteria that take up residence in the gut are friendly and even needed. We call these the beneficial bacteria. They help our bodies perform various tasks. They help us digest our food, they produce vitamins, and most importantly they help us keep a healthy gut. In exchange for all the hard work that the gut microbiota does for us, we provide the bacteria with a nice, safe, and warm place to live.

Beneficial bacteria have another super important task: they prevent harmful bacteria from getting out of control. As long as the number of harmful bacteria is kept to a minimum, they are mostly harmless. However, if the conditions are just right, the number of harmful bacteria can grow too large. Too many harmful bacteria in the gut can be dangerous and make us sick.

When the balance between the harmful and beneficial bacteria and other microbes changes, we use the term dysbiosis to say that the gut microbiota is out of balance [1]. Dysbiosis is characterized by

1. A reduction in the number of types of microbes present, or less diversity;

\section{Loss of beneficial microbes; and}

\section{Growth of harmful microbes (Figure 1).}

Beneficial and harmful bacteria are constantly in competition for food. One of the most important parts of their diet is iron, a mineral that is

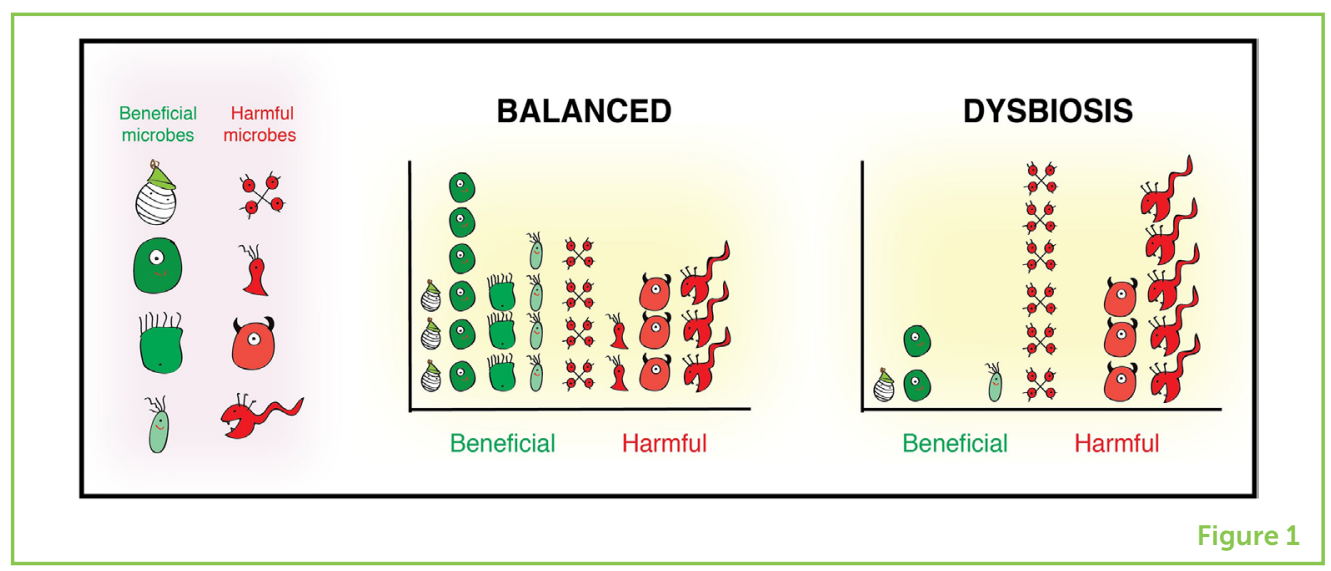




\section{HEME}

A ring-like molecule to which an iron atom is attached. The iron attached to heme binds oxygen in the lungs and releases it as the blood flows through the tissues of the body.

\section{Figure 2}

The battle for iron between bacteria in the gut. also required for our bodies to function properly. The more iron in their environment, the more the bacteria can grow.

\section{THE BATTLE FOR IRON}

Almost all living organisms, including humans, need iron to survive. Microbes, including bacteria, are no exception. Iron in the gut can either be bound to special molecules, like one called heme, or unbound (free iron). However, there is not enough iron for all the bacteria, so they are constantly fighting to capture the iron that is available (Figure 2).

Different bacteria have different ways of grabbing iron for themselves. In the battle for iron, beneficial bacteria are often at a disadvantage. Compared with beneficial bacteria, harmful bacteria have many more ways to grab iron. They can steal free iron or even big molecules that contain iron, including heme.

\section{IRON OBTAINED FROM FOOD}

There are two types of iron in our food: heme iron and non-heme iron. Heme iron is found in animal proteins, that is, in meat, such as poultry, red meat, and seafood. Non-heme iron and free iron are found in plant-based foods, like beans, fruits, grains, nuts, seeds, and leafy green vegetables.

For humans, one of the best sources of iron is red meat, which is rich in heme. Red meat includes beef, goat, lamb, and pork, to name a few. Heme iron is also found in "white meat," such as chicken or fish, but in much smaller amounts.

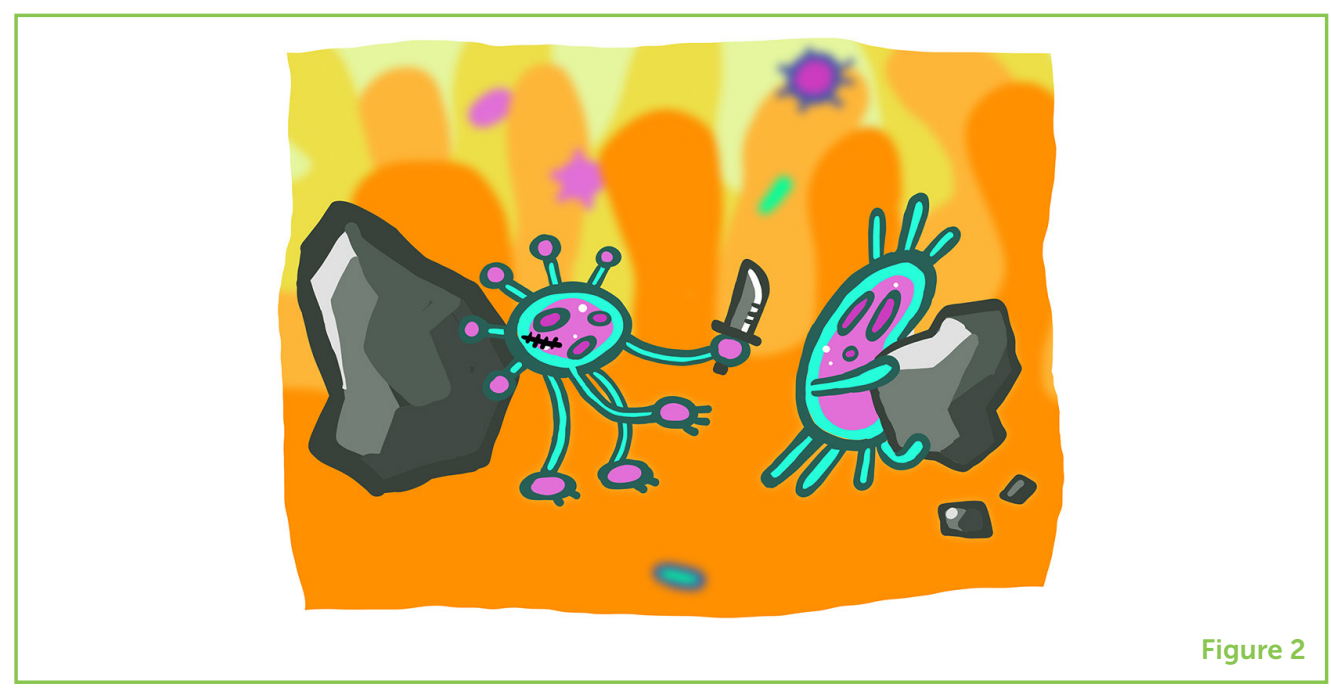


Because bacteria compete for iron, our research group questioned how heme iron would affect the balance between the beneficial and harmful bacteria in the gut. If we eat food that has a lot of heme iron, could there be a worsening of certain intestinal diseases?

\section{HEME IN FOOD CHANGES GUT MICROBIOME}

To answer our question, we performed a simple experiment using mice (Constante et al., 2017). We fed one group of mice food containing non-heme iron and the second group of mice got food containing heme iron. Both groups of mice were fed exactly the same amount of iron, so the difference was just in the type of iron, heme, or non-heme. We then collected the feces (poop) from the mice and analyzed the beneficial and harmful bacteria in the feces, which tells us which bacteria are present in the gut microbiota. We found that eating food with a lot of heme several days in a row changed the gut microbiota of the mice. There was an increase in harmful bacteria and a loss of beneficial bacteria. The gut microbiota became imbalanced.

Additionally, we found that mice fed the heme-enriched food were more likely to rapidly develop more severe forms of intestinal diseases, such as inflammatory bowel disease and colon cancer, compared with mice fed the food with iron that did not contain heme.

We repeated our experiments several times to show that the results could be reproduced. Altogether, our experiments helped to show how heme might be damaging the gut by causing an imbalance in the gut microbiota.

\section{WHY SHOULD WE EAT RED MEAT, BUT IN MODERATION?}

Have you ever heard someone say, "too much of a good thing?" Well, eating too much red meat can be just that. Eating too much red meat may help certain intestinal diseases to develop, such as inflammatory bowel disease and colon cancer. However, eating red meat in moderation is good for our health.

Eating some red meat is good, because heme is one of the best sources of iron. Heme is what the cells in our blood use to carry oxygen through our bodies (Figure 3).

Our bodies need oxygen to provide energy to the muscles and brain. Not having enough iron, or iron deficiency, can cause low oxygen levels in the body, which can slow down both growth and brain development. 


\section{Figure 3}

Where is most of our iron? Inside blood vessels, we have red blood cells. Inside red blood cells we have hemoglobin. Inside hemoglobin we have heme; and inside heme we have iron!

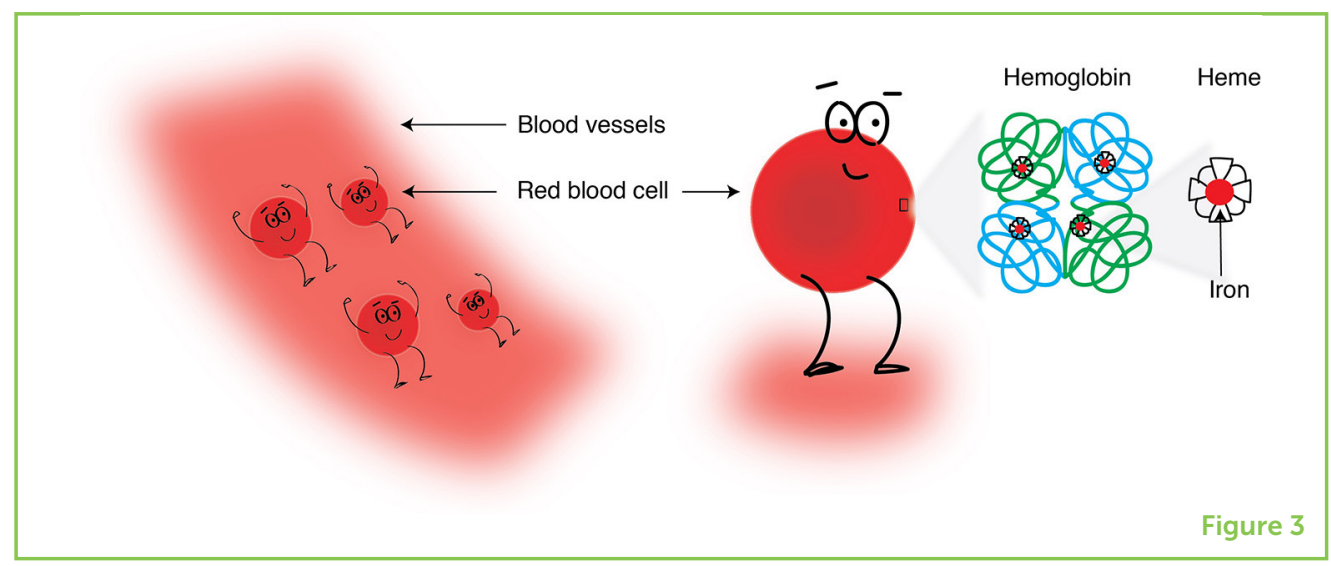

The body is better at absorbing the heme iron present in red meat than it is at absorbing the non-heme iron in other foods. This means that, as a source of iron, red meat remains a very important part of a healthy and balanced diet.

So, should we eat red meat? Yes! If it is a part of your diet, red meat can be consumed, but in moderation.

\section{CONCLUSION}

Our study shows that the gut microbiota can become imbalanced if mice eat food that contains high amounts of heme every day. However, we and other researchers have found that in mice, as well as in humans, the gut microbiota can quickly change when eating different foods [2]. This means that eating less red meat (less heme) could reverse the negative effects of heme in the gut.

We have learned a lot about the effects of heme in the gut, but we still have questions. For example, we know that antibiotics kill bacteria, which changes the balance of the gut microbiota to an extreme. So, should people eat red meat when taking antibiotics? This is another topic for study. In science, we always continue to ask questions so that we can better understand our bodies.

So, how much is too much red meat, under normal conditions? To reduce the risk of intestinal diseases, it is recommended that we eat no more than one serving of red meat per day, and up to $500 \mathrm{~g}$ a week, which equals a little less than three hockey pucks worth of steak. The risk of getting certain intestinal diseases increases when people eat more than $700 \mathrm{~g}$ of red meat per week (four hockey pucks).

Remember that red meat includes beef, lamb, and pork, so, you may eat white meats low in heme iron, which include poultry and fish, on 
some days. So, do not be boring, and eat a balanced diet for a happy and healthy gut.

A well-balanced gut starts with a well-balanced diet.

\section{AUTHOR CONTRIBUTIONS}

MC and MMS designed the study. MC, AW and MMS wrote the manuscript. VB designed Figures 1 and 3. We thank James Walker for Figure 2.

\section{ORIGINAL SOURCE ARTICLE}

Constante, M., Fragoso, G., Calvé, A., Samba-Mondonga, M., and Santos, M. M. 2017. Dietary heme induces gut dysbiosis, aggravates colitis, and potentiates the development of adenomas in mice. Front. Microbiol. 8:1809. doi: 10.3389/fmicb.2017.01809

\section{REFERENCES}

1. Petersen, C., and Round, J. L. 2014. Defining dysbiosis and its influence on host immunity and disease. Cell. Microbiol. 16:1024-33. doi: 10.1111/cmi.12308

2. David, L. A., Maurice, C. F., Carmody, R. N., Gootenberg, D. B., Button, J. E., Wolfe, B. E., et al. 2014. Diet rapidly and reproducibly alters the human gut microbiome. Nature 505:559-63. doi: 10.1038/nature12820

SUBMITTED: 14 July 2018; ACCEPTED: 15 January 2019;

PUBLISHED ONLINE: 12 February 2019.

EDITED BY: Suzanne Phelan, California Polytechnic State University, United States

CITATION: Constante M, Bharat V, Walker A and Santos MM (2019) Why We Should not Eat Red Meat at Every Single Meal. Front. Young Minds 7:6. doi: 10.3389/ frym.2019.00006

CONFLICT OF INTEREST STATEMENT: The authors declare that the research was conducted in the absence of any commercial or financial relationships that could be construed as a potential conflict of interest.

COPYRIGHT @ 2019 Constante, Bharat, Walker and Santos. This is an open-access article distributed under the terms of the Creative Commons Attribution License (CC BY). The use, distribution or reproduction in other forums is permitted, provided the original author(s) and the copyright owner(s) are credited and that the original publication in this journal is cited, in accordance with accepted academic practice. No use, distribution or reproduction is permitted which does not comply with these terms. 

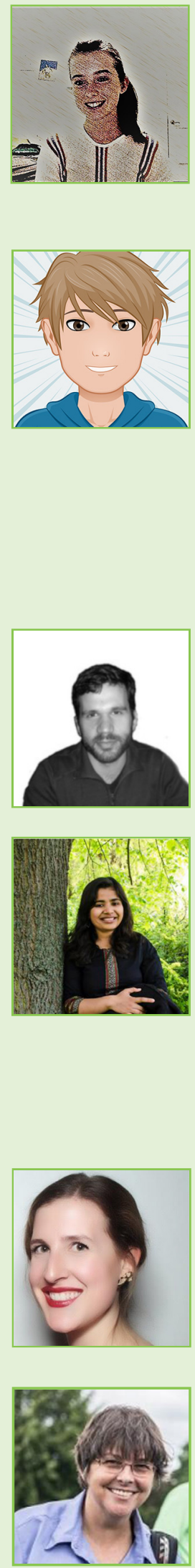

\section{YOUNG REVIEWERS}

\section{SIENNA, AGE: 12}

Hey, I am Sienna. I like Soccer, Basketball, and Music. I have two siblings and three pets, a dog, a cat, and a gecko. I like holding my cat (Max) and sleeping ;) I am currently in seventh grade. I take a debate class there, which may be my favorite class.

\section{TYLER, AGE: 11}

I am a creative, active sixth grader who is interested in learning more about the world around me. I enjoy many activities including music, art, cooking, soccer, and swimming. I love school and spend a lot of time reading. I enjoy books in the categories of mystery and fantasy but also enjoy non-fiction. I like making slime and playing board games with my family. The beach is one of my favorite locations. I am a great actor and have been in many productions!

\section{AUTHORS}

\section{MARCO CONSTANTE}

I am a Biologist that specialized in Molecular Biology. I continue to be amazed by how such tiny molecules interact to build up complex organisms. *msconstante@gmail.com

\section{VINITA BHARAT}

I am a Postdoctoral Researcher in Department of Neurosurgery, Stanford University, USA. While I enjoy "being a scientist", I developed an appetite to communicate science to a broader audience. To present science in fun and an easier way by using my sketching pencils and comic timings, I started a platform called "Fuzzy Synapse" (http://fuzzysynapse.com). Bridging this gap with the illustrations and cartoons is what I love to do through this platform. I am a fun, enthusiastic, and curious person, passionate about traveling who loves celebrations and bringing smiles.

\section{AMELIA WALKER}

Following my Bachelors of Science, I traveled the world as a Doping Control Officer. After visiting 23 countries I am happy to be back in her hometown of Montreal, working for the Cancer Department at the Centre Hospitalier de l'Université de Montréal.

\section{MANUELA M. SANTOS}

I am a Professor at the University of Montréal (Québec province), in Canada. I studied Biology, specializing in Immunology and Microbiology. When I am not busy trying to figure out how things work, I can be found playing guitar, hiking with friends, or enjoying a tennis match or two. 